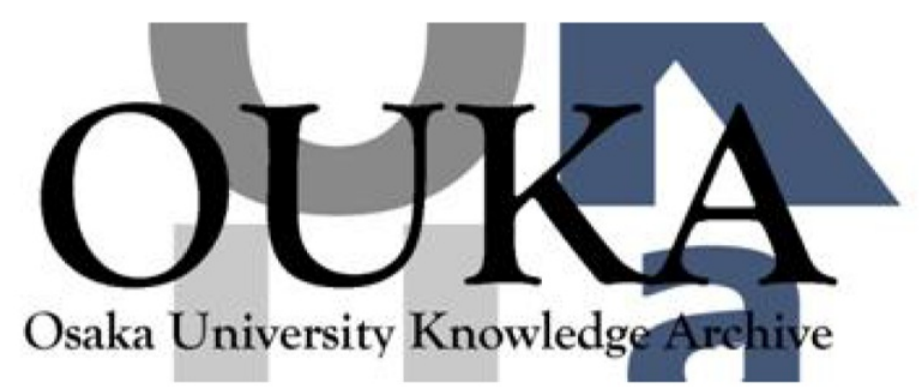

\begin{tabular}{|c|l|}
\hline Title & Mechanical Effects of Welding \\
\hline Author(s) & Ueda, Yukio \\
\hline Citation & Transactions of JWRI. 20(2) p. 319-p.326 \\
\hline Issue Date & $1991-12$ \\
\hline oaire:version & VoR \\
\hline URL & https://doi.org/10.18910/10390 \\
\hline rights & \\
\hline Note & \\
\hline
\end{tabular}

Osaka University Knowledge Archive : OUKA

https://ir. Library. osaka-u. ac. jp/

Osaka University 


\title{
Mechanical Effects of Welding
}

\author{
Yukio UEDA*
}

\begin{abstract}
For joining components of steel structures, such as ships, offshore structures, steel bridges, welding is the most common and effective method. By welding, methllugical changes, welding defects, welding distorsion, residual stresses, etd. may be produced. These may give important effects on the performance of welded joints and structural components. This paper will outline, on a tutorial level, the comsequences and mechanical effects of welding.
\end{abstract}

KEY WORDS : (Mechanical Effect) (Welding Imperfection) (Low-Matched Joint) (Compressive Strength) (Unstable Fracture) (Fatigue Strength)

\section{General}

When steel structures such as ships, offshores are constructed, many kinds of processing such as cutting, forming, joining including welding are required.

Among the many methods of joining steel, welding is the most common and effective. Welding is a kind of metallurgical joining method involving the melting of the metal in the vicinity of joint. Welding processes may be categorized into two kinds, fusion welding and resistance welding. Here, attention is restricted to fusion welding for steel structures. When structural components are joined or connected with other components by fusion welding, heat input is provided, which melts the metal along the joint and holds the components together after cooling down. As a consequence of this processing, metallurgical changes, welding defects, welding distortion, residual stresses, and metallurgical and mechanical heterogeneities may be produced. These may give important effects on the performance of welded joints and structural components, such as buckling, stable and unstable fractures, fatigue strength.

Based on recent research ${ }^{1)}$, this paper will address, on a tutorial level, the consequences and mechanical effects of welding.

\section{Consequences of welding}

\subsection{Mechanical and metallurgical heterogeneities of welded joints}

In a sigle weld, at the instant when the weld metal is laid, the temperature suddenly increases locally and most of the heat is transmitted through the base plate by conduction with the remainder mostly passed to the air by convection. Consequently, a point at a distance away from the welding line is also slowly heated with the temperature reached being in proportion to distance from the weld. The thermal cycles at individual points in the plate will therefore vary. The situation also becomes much more complex in multi-pass welds. The mechanical properties of the welded joint changes according to the thermal cycle experienced and will be influenced by many factors such as the kind of steel, its chemical composition, the highest temperature attained, cooling rate in the thermal cycle and the number of thermal cycles.

Typical distributions of strength, elongation and ductility of welded joints of mild steel and heat-treated high strength steel are demonstrated in Figs.1 and $\mathbf{2}^{2)}$.

\subsection{Welding residual stress}

In the case of a butt welding joint, the heat input from welding produces unsteady and uneven temperature distribution in the joint. This causes compressive plastic strain in the vicinity of the weld line, which is the main source of welding residual stress. As a results, a tensile stress zine is generated in a narrow width along the weld line with compressive stress zones on its both sides being produced so as to satisfy the self-equilibrating condition. The pattern of welding residual stress distribution of a butt welded plate is dependent upon the ratio of length to breadth of the plate as shown in Fig. $3^{3)}$. The pattern for the flange and web of built sections is very similar.

In a butt welded plate of high strength steel such as HT80, the residual stresses in the weld metal and heat affected zone are lower than the yield strength of the materials since volume expansion due to phase trans $\dagger$ Received on Nov.9,1991

* Professor
Transactions of JWRI is published by Welding Research Institute, Osaka University, Ibaraki, Osaka 567, Japan 

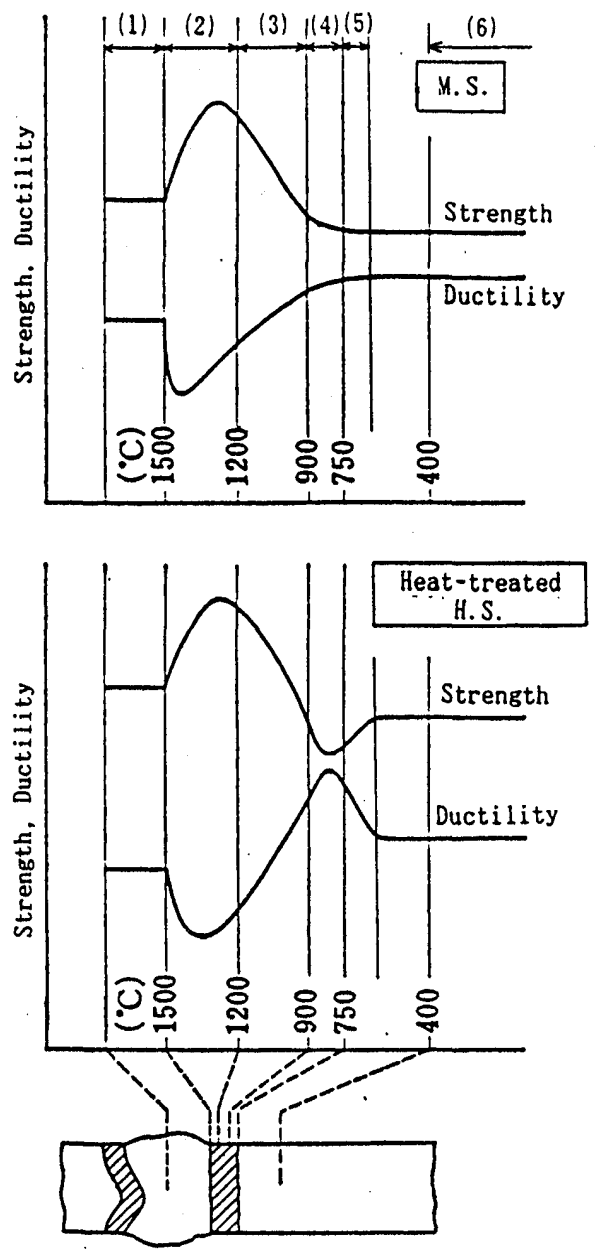

Fig. 1 distributions of strength and ductility of welded joints (mild steel and heat-treated high strength steel)

formation at the cooling stage reduces the magnitude of compressive plastic strain.

In the case of multi-pass welds of thick plates welding residual stress distributions are complex. As an example, those for narrow gap butt-welded joints of thick plate (MS $50 \mathrm{kgf} / \mathrm{mm}^{2}$, thickness: $50 \mathrm{~mm}$ ) with 20 passes $/ 20$ layers are shown for two extreme restraining conditions; in the restraint condition $A$, the rotation of plates due to welding is free and in the restraint condition $B$, the rotation is completely restrained in Fig. $\mathbf{4}^{4}$. Condition $A$ produces large tensile stress at the root of welds and indicates possibility of root cracking.

\subsection{Welding deformation}

- Types of welding deformation -

Welding deformation may be classified as either inplane deformation or out-of plane deformation. Special attention is paid to the latter, which it may be divided into three categories.

(1) Angular deformation

This is generated along the butt weld line and fillet weld line due to the shrinkage of weld
(1) Fusion metal
(2) Coarse grained $\mathrm{HAZ}$
(3) Fine grained $\mathrm{HAZ}$
(4) Intercritical $\mathrm{HAZ}$
(5) Subcritical HAZ
(6) As-received parent metal

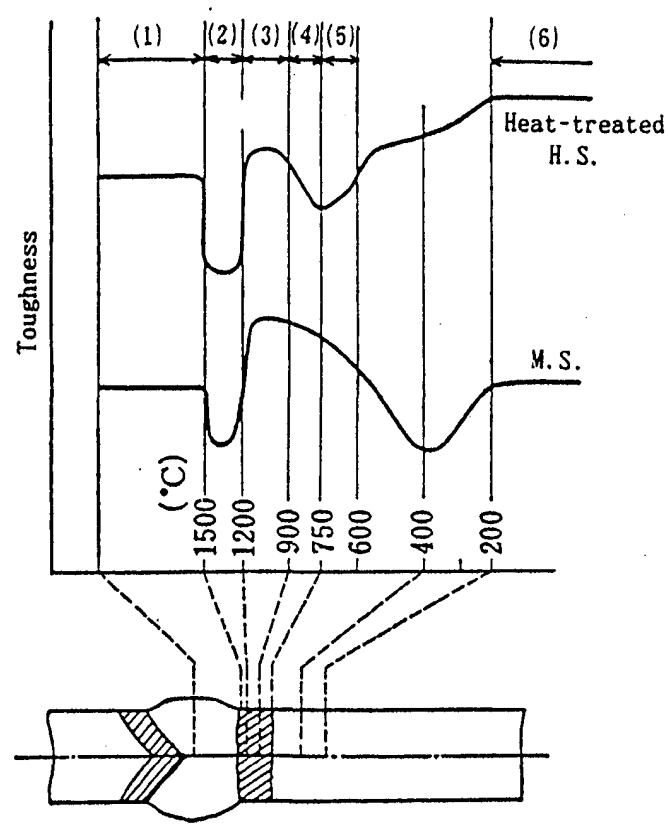

Fig. 2 distribution of toughness of a welded joint (mild steel and heat-treated high strength steel)

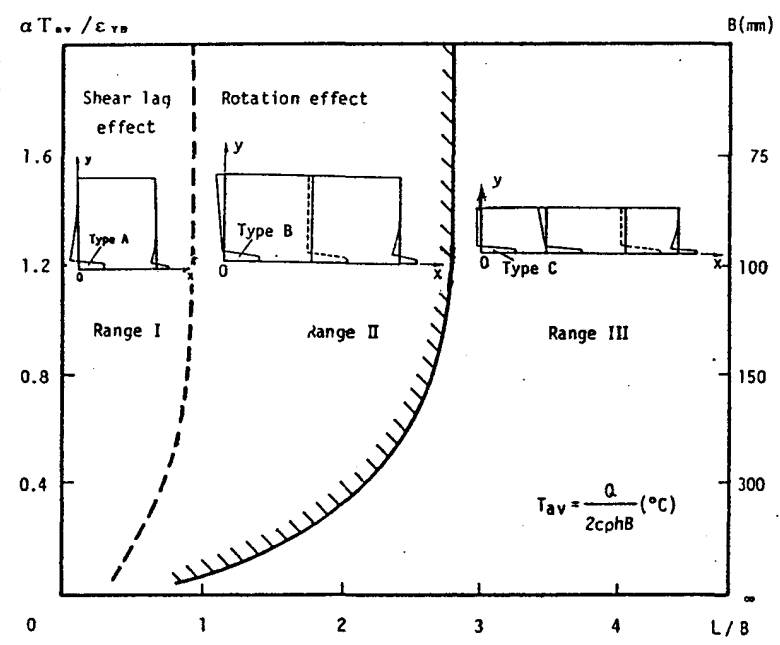

Fig. 3 Classification of residual stress distribution by aspect ratio $L / B$

metal.

(2) Longitudinal flexural deformation

Longitudinal flexural deformation is observed in welded built-up columns and beams.

(3) - Buckling deformation

This defotmation is observed in plate elements surrounded by stiffeners, beams, etc. which are attached by fillet weld. 


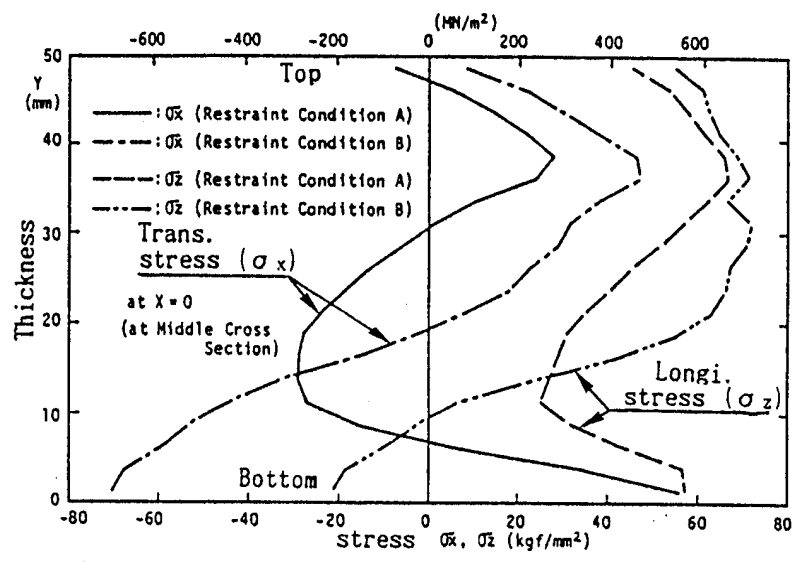

Fig. 4 Calculated welding residual stresses in multi-pass batt welds at the middle cross section

Angular distortion of fillet weld yields cylindrical deformation and simultaneously longitudinal compressive residual stress amplify the buckling mode deformation.

\section{- Modes of welding deformation -}

Usually, welded built-up columns of uniform crosssection may not be perfectly straight. Welding deformation along the longitudinal axis may be decomposed into overall and local components which are represented in a series of - sinusoidal functions. The fundamental mode of deflection may have the largest magnitude and may coincide with the fundamental mode of buckling or collapse mode, which is most influential upon the strength. Of built-up sections of thin plate, local deformation as discussed below, is also produced similar to that for plate elements.

The welding deflection of a long rectangular plate, $w_{o}$, may be expressed by a series of sinusoidal functions.

$$
w_{\mathrm{o}}=\Sigma A_{\mathrm{om}} \sin (m \pi x / a) \sin (\pi y / b)
$$

The magnitude of each coefficient $A_{\text {om }}$ decreases as the number of mode increases. Although the amplitude of the first mode is largest, this is not influential up on the strength, since this does not coincide with the buckling mode or the collapse mode. This is one of the fundamental differences in the effects of initial deformation on plates compared to columns.

\subsection{Weld defects and misalignment}

Various weld defects may be observed in the weld metal and its vicinity. They are: (1) weld cracking in the weld metal and HAZ, (2) blowhole, (3) inclusion, (4) lack of penetration, (5) undercut, (6) Overlap

They are sources of stress concentration and weld cracks in particular are most dangerous since they have very sharp tips and, in some cases, large cross-sectional area.

\section{Mechanical effects of welding}

\subsection{Buckling and ultimate strengths of welded joints of overmatching}

As described above, in the case of mild steel, the strength of the weld metal and heat affected zone of a welded joint is higher than the base plate. This is socalled overmatching. On the other hand, in the case of heat-treated high strength steel, this strength is lower than the base plate, that is, low strength zone exists. This is socalled undermatching.

The strength of overmatched joint can be regarded as the same as the base plate. In contrast with this, the strength of undermatched joint is different, and will be described later.

\section{- Effects of welding residual stress ${ }^{5)}$}

When a column or a plate containing residual stresses is subjected to axial force until the member becomes fully plastic, the average stress-strain relation of the member is different from that of the original material (as shown in Fig.16 on p.334, Ref.1)). Since the super position of the applied stress to the residual stress causes local yielding at a lower average stress than the yield stress under either tension or compression being applied.

This implies that the rigidity of the member is affected by the existence of residual stresses. However, as the welding residual stresses are assumed to be selfequilibrating, the total load carrying capacity is the same as that of the plate free from residual stress.

When a column of uniform cross-section containing residual stresses is subjected to concentrated load $P$ at the center of cross-section, the effect of residual stress is observed in the elastic buckling.

In the case of a column with two symmetric axes of the cross-section, either flexural or pure torsional buckling takes place independently. The residual stresses affect only torsional buckling but flexural buckling since torsional buckling is similar to flexural buckling of a plate. In the case of a column with single symmetric axis or no symmetric axis, coupling of flexural and torsional bucklings occurs and the residual stresses influence the elastic buckling strength.

When plastic portion in a cross-section spreads by an increases of the load, effective elastic portion is reduced. This causes reduction of the flexural and torsional regidities of the section and in some cases additional eccentricity. Therefore, residual stresses influence both the elastic buckling and inelastic buckling.

When a flat plate containing residual stresses $\left\{\sigma_{r}\right\}=$ $\left\{\sigma_{x r}, \sigma_{y r}, \tau_{x y r}\right\}^{T}$ is subjected to in-plane stresses, $\{\sigma\}$ $=\left\{\sigma_{x}, \sigma_{y}, \tau_{x y}\right\}^{T}$, the residual stresses affect elastic 
buckling strength of the plate, since the residual stresses contribute the internal work done by the deformation due to buckling.

When the applied stresses increase, plastic portion initiates where the sum of $\{\sigma\}+\left\{\sigma_{r}\right\}$ satisfies the yield condition. Then, the stress distribution becomes elasticplastic. The rigidity of this portion is lower than that of elastic portion. This is the second effect of residual stresses on elastic-plastic buckling of plate elements. When the compressive residual stress is larger than the critical value, the plate buckled after welding without being subjected to any external loads.

\section{- Effects of welding distortion -}

The component of fundamental overall mode of welding initial deflection reduces axial rigidity and the carrying capacity of a column (ultimate strength) due to large deflection and additionally due to plastic deformation by bending. The compressive ultimate strength of a column with initial imperfection, which are initial de fection and residual stresses, is given by socalled column curves which were obtained theoretically and experimentally by many investigations. When welding deformation is observed in components of a built-up column, local deflection reduces the local strength and rigidity as will be seen on plates. In this case, the restraining condition around the components, such as web and flange, plays an important role on the local behavior. Reduction of local strength and rigidity results in reduction of overall strength and rigidity of the column.

When a long simply supported rectangular plate with actual initial deflection is subjected to compression, all components of the initial deflection expressed by a series of sinusoidal functions are amplified roughly in the same proportion by an increases of load until the load reaches nearly the critical level assuming perfectly elastic behavior, (as represented in Fig.17 on p.338 of Ref.1)).Even in this process, in-plane stiffness is smaller than that of a flat plate. Above this load, all components decrease except one which becomes predominant. This deflection made is selective in that it indicates the lowest possible collapse load.

In the case of thin plate, the ultimate strength state is attained after the elastic deflection mode becomes stable and the stable collapse deflection mode is equal to or one or two modes higher than the buckling made. In the case of long thick plates, the collapse mode is determined by plastic deforemation initiated from most stressed fibres near the loading edges, which is strongly dependent upon the curvature of the initial deflection, before elastic stable deflection mode is attained.

The aspect ratios of a plate which gives the minimum buckling strength and the ultimate strength are different.
In the case of a simply supported rectangular plate, the minimum buckling strength for $m$ half waves is obtained for the aspect ratio being $m$. This implies that the aspect ratio of one half wave for the minimum buckling strength is 1.0 , and that for the minimum ultimate strength is between 0.5 to 1.0 depending upon the slenderness ratio, the magnitude of initial deflection etc. If initial deflection is composed of many modes, such appropriate deflection mode as to attain the minimum ultimate strength is automatically selected, (as shown in Fig.19 on p.338 of Ref.1)). Except for the aspect ratio approximately below 0.5 , the minimum ultimate strength is regarded as constant irrespective to the aspect ratio, and this is influenced mostly only by the magnitude of the same component deflection as the collapse mode.

\subsection{Ductile strengths of welded joints containing low strength zone}

- Ductile strength in tension -

when a welded joint containing a lower strength zone is subjected to tension perpendicular to the weld line, the yielding starts at the lower strength zone and the plastic deformation is constrained by the higher strength zone of the base plate. Consequently, the yield strength increases as the plastic deformation proceeds, since the triaxial effect increases the yield stress.

As the length of low strength zone decreases, the strength of the joint increases to that of base plate. When the length is shorter than a certain limit, the strength reaches that of base plate and ductile fracture may occur in the zone of base plate. The strength of the welded joint is influenced by

(1) The ratio of length of low strength zone to thickness: $X_{h}=H / h$

(2) The ratio of the width of joint to thickness

(3) The ratio of low yield strength to the strength of base plate: $S_{r}=\sigma_{T}{ }^{W} / \sigma_{T}^{B}$

The strength of joint containing low strength zone may be evaluated as shown in Table $\mathbf{1}^{6}$.

- Strength and rigidity of the joint under bending -

When a butt joint containing low strength zone is subjected to bending, yielding of the low strength zone occurs first and its plastic deformation is restrained by the base plate in the similar manner to the case of tension. This causes decreases in flexural rigidity after the first yielding and plastic collapse strength.

When pure bending moment is applied to the beam containing low strength zone, as shown in Fig. $5^{7}$, the relationship between load and deflection at the loading points is obtained experimentally as illustrated in the same figure. Compared with the relationship of a beam of base plate only, the reduction of flexural rigidity may be 
Table 1 Formulae for ductile strength of welded joints containing low strength zone
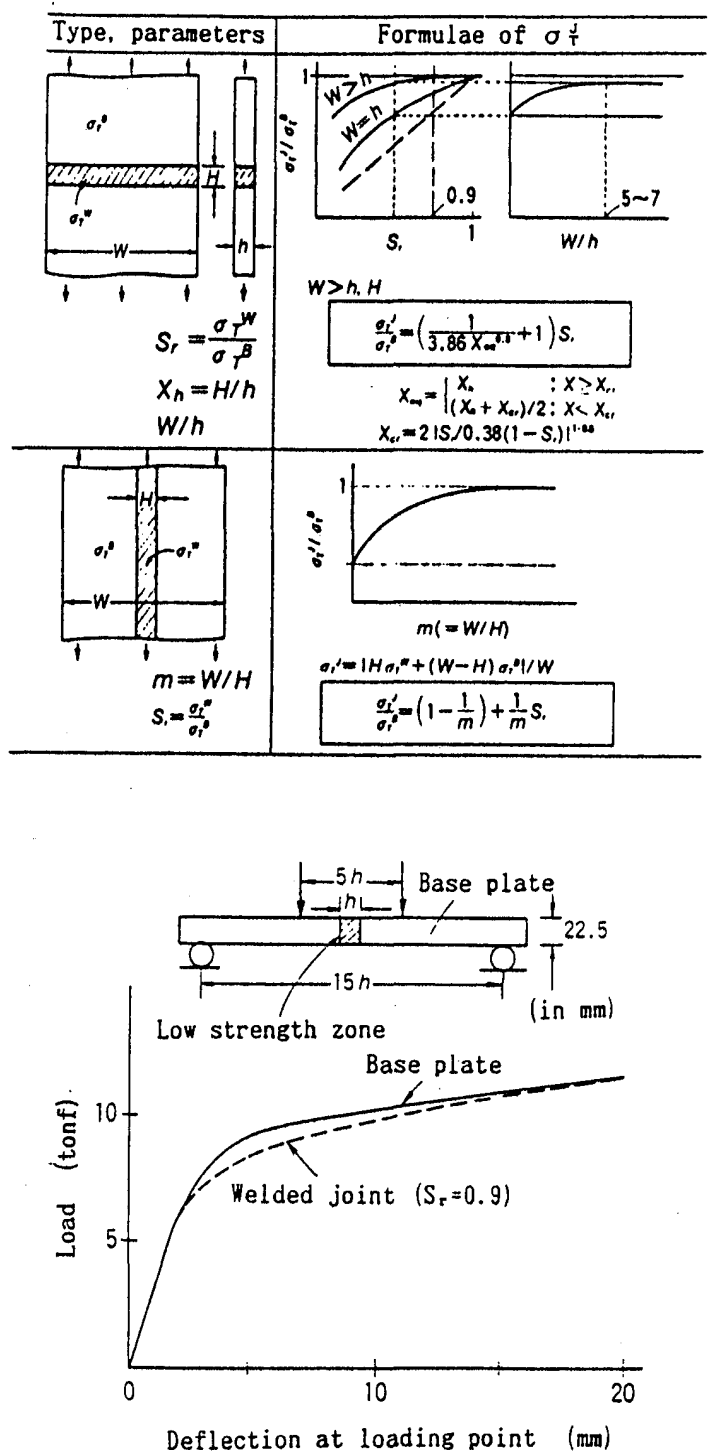

Fig. 5 Load-deflection curves of two beams (base plate only and welded joint containing low strength zone. $S_{r}=0.9$ )

rather small except for special cases where the length of low strength zone is long or the strength of the zone is extremely low.

- Plastic collapse strength -

As an example of plastic collapse of a beam containing a low strength zone, the both end fixed beam under uniformly distributed loads is considered. The plastic collapse mode is formed by two plastic hinges at both ends and one in the middle portion.

The plastic collapse load is largely dependent upon the location of a low strength zone and its length, since the strength of fully plastic sections governs the plastic collapse load. In the most extreme case where the low strength zone is in the middle of the beam, the collapse strength is an average of the collapse strengths of two homogeneous beams of base plate and low strength material.

- Compressive strength of columns and plates -

The compressive ultimate strength of a column with low strength zone at the midlength is analyzed by FEM, assuming that the column is initially deflected by the magnitude of thickness $/ 1000$ at center, the length of low strength zone is the same as the thickness and the yield strength of low strength zone is $80 \%$ of the base plate, that is, $S_{r}=0.8$. The ultimate strength of slender column (elastic buckling) is affected very little by the existence of low strength zone, but in the case of the shorter columns (plastic buckling), the ultimate strength decreases approximately to $80 \%$ of that of a homogeneous one.

The compressive ultimate strength of square plates with low strength zone is analyzed by FEM. First, it is assumed that square plates have three different slenderness ratios as shown in Table $2^{8)}$, and the width of low strength zone is the same as the plate thickness along the supporting boundary and twice the plate thickness for the joint inside the boundary. The theoretical ultimate strength is shown by the ratio to that of a square plate without low strength zone in Table 2 . When the compressive force is applied to the plate in the same direction as the joint, the reduction of ultimate strength is negligibly small.

\subsection{Unstable fracture of welded joints}

Most fractures of welded structures initiate from weld defects, especially weld cracks such as plane cracks, fatigue cracks and various types of stress concentration. Welding residual stress and distortion also influence the fracture strength in various ways dependent upon the type of fracture which in turn is governed by temperature $T$. Additionally, heterogeneities in mechanical and metallurgical properties of a welded joint have some effects on the fracture.

\section{- Types of fracture -}

First, the types of fracture of a welded joint containing a sharp crack which is an idealization of a sharp weld defect will be described (Fig. 6 $^{9}$ ).

(1) $T<T_{Y} ; \sigma_{N}<\sigma_{Y}$ (low stress brittle fracture). The specimen is in the small scale yielding state.

(2) $T_{Y}<T<T_{L} ; \sigma_{N}>\sigma_{Y}$ (high stress brittle fracture).

The specimen is in the full yielding state. The overall strain at the fracture is small and the fracture surface is brittle.

(3) $T_{L}<T<T_{S} ; \sigma_{\text {oo }}>\sigma_{Y}$ (unstable ductile fracture with ductile crack) 
The specimen is in the general yielding state.

(4) $T_{S}<T ; \sigma_{o o}>\sigma_{Y}$ (stable ductile fracture with stable ductile crack propagation)

\section{- Effect of welding residual stress -}

In order to furnish a specimen containing a crack in the weld, there are two procedures. One is to provide a crack to a specimen before welding and another is to provide a crack after welding. In both cases, a crack is machined perpendicular to the weld line. The tensile residual stress does not generate any stress normal to the crack surface. However, large tensile stress above the yield stress is produced in the vicinity of the notch tips and a large amount of plastic strain is produced.

According to the CTOD criterion, the plastic strain produced by the welding residual stress influences differently the fracture stress for the various fracture types. The influences of the welding residual stress is

Table 2 Relative strength of plate with low strength zone compared to homogeneous plate computed by FEM and idealized model $\left(w_{o}=\mathrm{t} / 1000\right)$

\begin{tabular}{|c|c|c|c|c|c|c|}
\hline & $\begin{array}{l}b / t . \\
\sqrt{\sigma_{Y} / E}\end{array}$ & s. s. & 5. 5. & s. s. & clamoed & $\begin{array}{l}\text { OTIA } \\
\text { s. s. }\end{array}$ \\
\hline E.B.M. & 2.0 & $\begin{array}{c}0.997 \\
(1.000)\end{array}$ & $\begin{array}{c}0.939 \\
(0.949)\end{array}$ & $\begin{array}{c}0.980 \\
(0.941)\end{array}$ & 0.976 & 0.861 \\
\hline T.8.M. & 1.0 & $\begin{array}{r}0.973 \\
(0.987) \\
\end{array}$ & $\begin{array}{l}0.962 \\
(0.924)\end{array}$ & $\begin{array}{c}0.913 \\
(0.916) \\
\end{array}$ & 0.915 & 0.815 \\
\hline P.8.M. & 0.5 & $\begin{array}{c}0.982 \\
(0.982)\end{array}$ & $\begin{array}{c}0.925 \\
(0.924)\end{array}$ & $\begin{array}{c}0.923 \\
(0.912)\end{array}$ & 0.924 & 0.800 \\
\hline
\end{tabular}
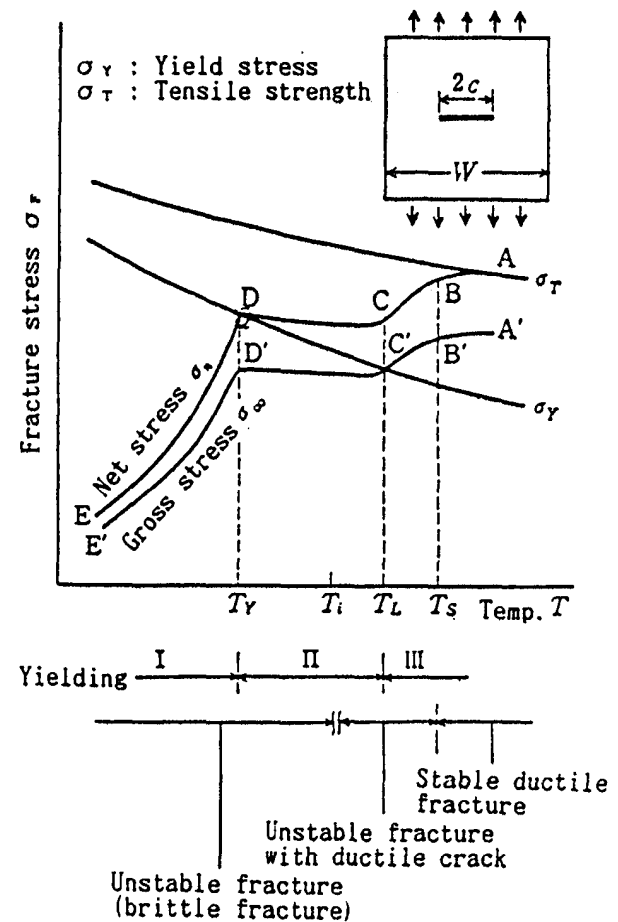

Fig. 6 Types of fracture of a plate with a center notch under different test temperatures illustrated in Fig. 7 and outlined as follows ${ }^{9,10)}$.

(1) $T>T_{S} ; \sigma_{\text {oo }}>\sigma_{Y}$

The residual stress does not affect the strength and ductility of the joint.

(2) $T_{L}<T<T_{S}$

The residual stress does not decrease the fracture stress but overall strain.

(3) $T<T_{L}$

The fracture stress-temperature curve indicates an abrupt change at $T_{L}$ and the decrease of fracture stress due to the residual stress seems to be the maximum at $T_{Y}$.

- Effect of welding distortion -

Welding distortion and misalignment of welded joints increase stress and strain concentrations at the toes, undercuts etc. These result in reduction of the fracture stress. In the case of butt welded joints subjected to tension perpendicular to the weld line, the strain produced at the point of strain concentration such as at the toe is larger in an initially deflected specimen than in a straight one. Consequently, the fracture stress is reduced and the temperature $T_{L}$ (highest temperature for low stress brittle fracture) moves to higher temperature (Fig. 8 $^{11)}$ ).

The specimen with a surface notch is prepared, being imposed an initial angular distortion $\eta$ and misalignment $2 \omega_{1}$ as represented in Fig. $9^{12)}$.

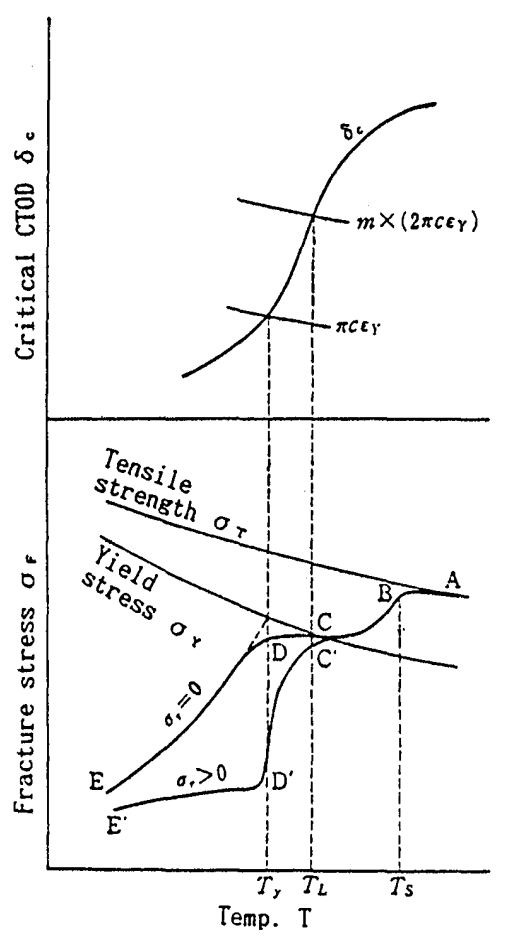

Fig. 7 Schematic representation of the effects of welding residual stress $\left(\sigma_{r}\right)$ on fractures at different test temperatures 
Changes in the stress intensity factor at the bottom of notch are calculated. When the notch is relatively shallow, the stress intensity factor increases about 1.8 time by the initial distortion and misalignment. This makes $T_{L}$ about $35^{\circ} \mathrm{C}$ higher than that without these initial imperfections in the case of heat-treated high strength steel of $50 \mathrm{kgf} / \mathrm{mm}^{2}$ class.

\section{- Effect of embrittlement in weld bond -}

The welded zone is subjected to thermal and strain cycles. These cause embrittlement of the weld zone, especially in the weld bond. According to bending tests of notched specimens, the critical CTOD $\left(\delta_{c}\right)$ of weld bond moves to higher temperature as shown in Fig. $\mathbf{1 0}^{2)}$. Attention should be paid to the case of large heat input since a large shift of the critical CTOD curves to higher temperature is observed.

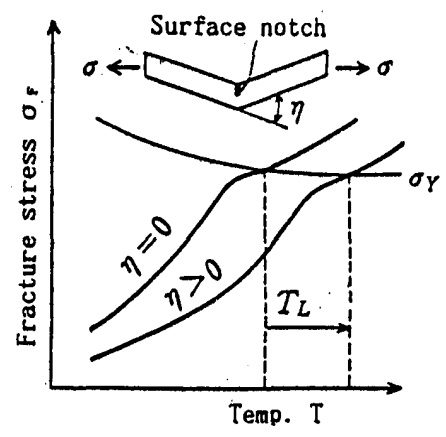

Fig. 8 Schematic representation of the effects of welding distortion on low stress brittle fracture

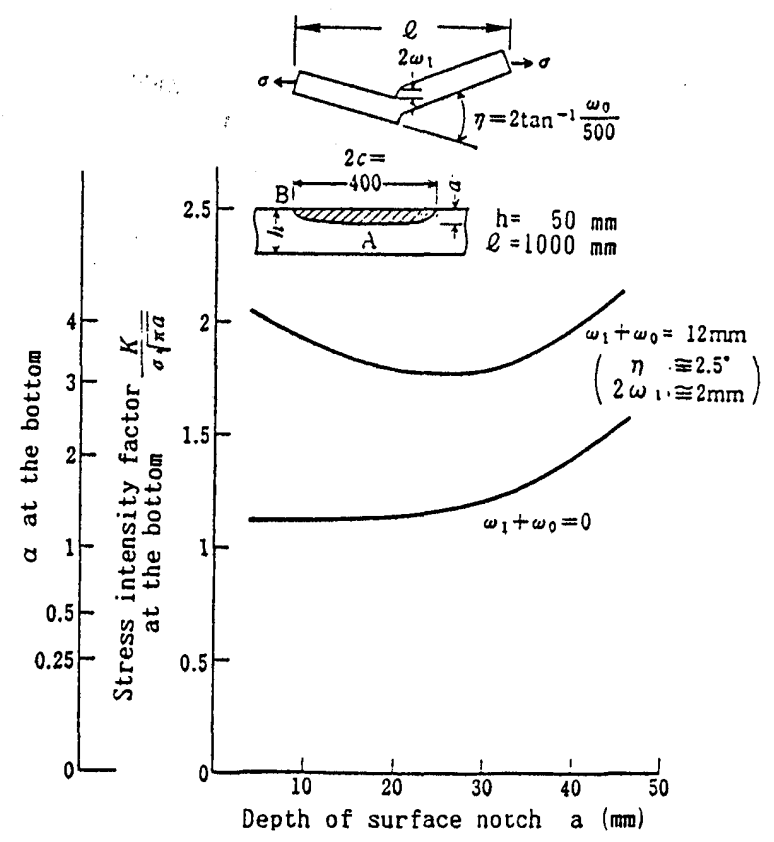

Fig. 9 Stress intensity factors at the bottom of surface notch of a plate with initial angular distortion and misalignment
- Effect of heterogeneity of mechanical properties -

As stated before, the yield strength of the weld metal and heat affected zone may be higher or lower than that of the base plate, which is called overmatching or undermatiching.

A notch is furnished in the weld metal of a plate parallel to the weld line and the plate is subjected to tension perpendicular to the weld line. The elasto-plastic behavior of welded joint of overmatching or undermatching is quite different from that of the base plate. The unstable fracture strength of the plate combined with either higher strength zone or lower strength zone is stated below ${ }^{13)}$.

(1) In the case of the same ductility at the notch tip, the welded joint of overmatching exhibits higher fracture strength and better ductility.

(2) In order to maintain the same ductility of welded joint of undermatching as for the case of overmatching, the fracture toughness of lower strength zone should be better than that in the case of overmatching.

\subsection{Fatigue strength of welded joints}

- Main causes of stress concentration of welded joints -

A principal governing factor of fatigue strength is the degree of stress concentration. In welded joints and welded structures, there are two main causes of stress concentration:

(1) Stress concentration peculiar to welded joints: Geometries at the toe and the root, and imperfection due to weld defects (weld crack, lack of penetration, blowhole, etc.)

(2) Stress concentration due to structual discontinuity:

When a welded joint is located at a structural discontinuity, the elastic stress concentration factor is expressed approximately by a product

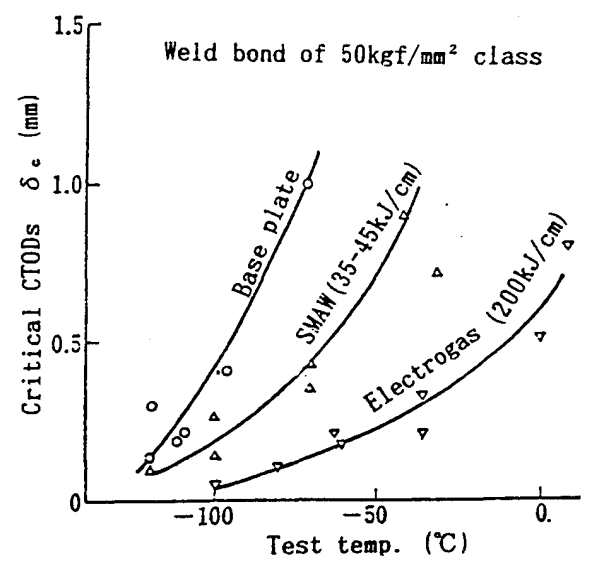

Fig. 10 Critical CTODs of weld bonds of welded joints prepared by different welding methods (bending test) 

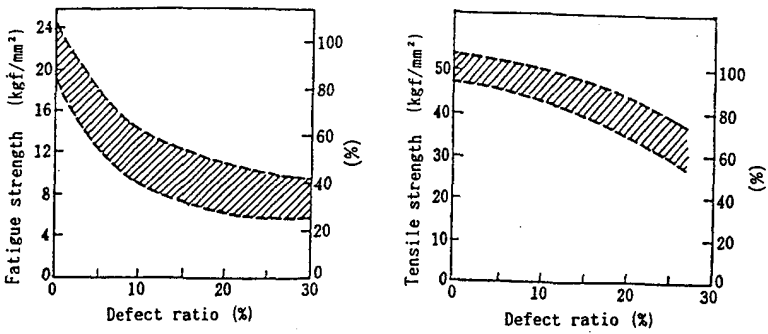

Defect ratio $\%=\frac{\begin{array}{l}\text { Total cross sectional area of weld defects } \\ \text { on the fracture surface }\end{array}}{\text { Cross sectional area of the fracture surface }} \times 100(\%)$

Fig. 11 Effects of weld defects on ductile fracture and fatigue strengths

of the above two stress concentration factors (1) and (2). Under these circumstances, a fatigue crack may be easily initiated there.

\section{- Effect of welding residual stress -}

When a butt-welded joint is subjected to a tensile stress in the welding direction, the stress in the tension zone of the residual stress distribution reaches yield stress and the magnitude of the tensile and compressive residual stresses are reduced after unloaded. During repeated loading, the residual stress distribution changes.

With regard to the effect of residual stress on fatigue strength, quite different conclusions have been delivered. It may be said that the effect on the initiation of fatigue crack is uncertain, but when the crack is initiated, the rate of crack propagation may be faster in the field of tensile residual stress and slower in the field of compressive residual stress ${ }^{14)}$.

\section{- Effect of weld defects and misalignment -}

Small weld defects such as blow holes, slag inclusion, lacks of penetration are considered to affect hardly the ductile strength of a welded joint, but remarkably the fatigue strength as represented in Fig. 11 ${ }^{15}$.

Results of high cycle fatigue tests on welded joints of $M_{n}-M_{o}$ steel without reinforcement indicates that the effects of blow holes, slag inclusions and lacks of penetration are regarded as same, but weld cracks reduces the fatigue strength greater than the other defects (Fig. 12).

\section{References}

1) Proceedings of the 10th ISSC, Vol.1, Lyngby, 1988.

2) Satoh, K., Mukai, Y. and Toyoda, M. "Welding Engineering", 1979, Rikogakusha, Tokyo, JAPAN (in Japanese)

3) Ueda, Y., Kim, Y.C. and Yuan, M.G.: "A Prediction Method of Welding Residual stress Using Source of Residual Stress (Report 1)", Trans. JWRI (Welding Research Institute, Osaka Univ.), Vol.18, No.1 (1989), pp.51-58.

4) Ueda, Y. and Nakacho, K.: "Three dimensional Welding

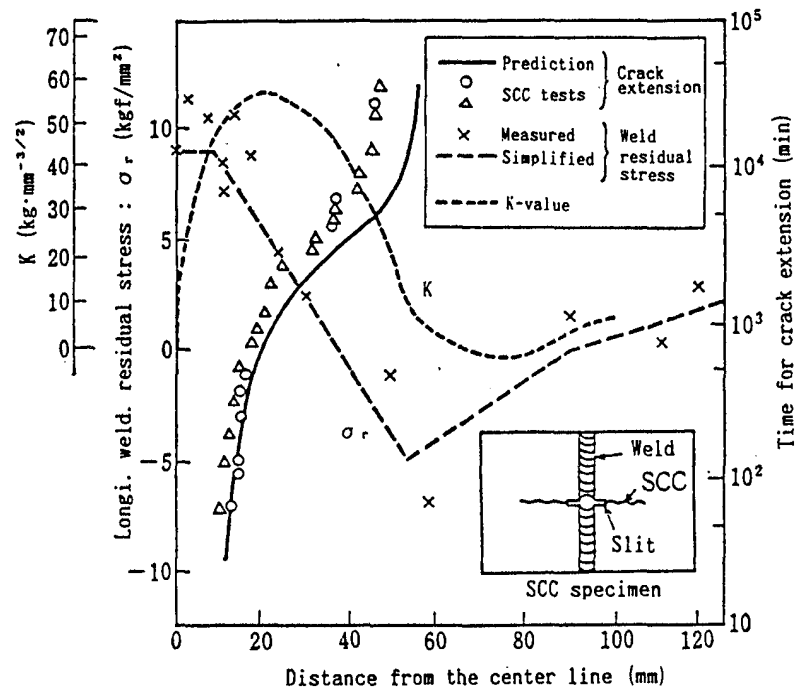

Fig. 12 Stress corrosion cracking of butt-welded joint of SUS304 in boiling water containing $42 \% \mathrm{Mg}_{\mathrm{g}} \mathrm{Cl}_{2}$

Residual Stresses Calculated and Measured", Proc. Int. Conf. on Effects of Fabrication Related Stresses on Product Manufacture and Performance, The Welding Institute (England), 1985.

5) Chapter 4, The role of Imperfections, in Ref.1.), pp.330-403.

6) Satoh, K. and Toyoda, M.: "Joint Strength of Heavy Plates with Lower Strength Weld Metal", Welding J1, Vol.54 (1975), p. 311s.

7) Toyoda, M.: "Mechanics for Heterogenous Materials [1V]", J. Japan Welding Society, Vol. 59, No.2 (1990), pp.78-83 (in Japanese).

9) Tetelman, A.S. and McEvily, A.J.Jr.: "Fracture of Structural Materials", John Wiley \& Sons., New York, (1970).

10) Satoh, K. and Toyoda, M.: "Effects of Residual Stress Mechanical Heterogeneity on Brittle Fracture Strength of Welded Joints", J1 SNAJ (the Society of Naval Architects of Japan),Vol.131 (1972), pp.335 (in Japanese).

11) Kihara, H. et al: "Effect of Notch Size, Angular Distortion and Residual Stress on Brittle Fracture Initiation Characteristics of Welded Joints for High Strength Steels (1st Report)", J1 SNAJ, Vol.125 (1969), pp.255 (in Japanese).

12) Kobayashi, A.S. and Moss, W.L.: "Stress Intensity Magnification Factors for Surface-flawed Tension Plate and Notched-round Tension Bar", 2nd Int. Conf. on Fracture, Brighton, England, (1968).

13) Satoh, K., Toyoda, M. and Itoh, Y.: "Deformation in Vicinity of Notch and Overall Strain of Notched Specimen beyond General Yielding", J1 SNAJ, Vol.142 (1977), pp.141, (in Japanese).

14) Masubuchi, K.: "Analysis of Welded Structures", Pergamon Press, (1980).

15) Watanabe, M. And Komachi, K.: "Relation between Welding Defects and Mechanical Strength for welded Joints”, J1 JWS, Vol.30, No.6 (1961), pp.376, (in Japanese). 